\title{
A DFT-D study of stacking interactions between substituted buckybowls with fullerenes
}

\author{
Daniela Josa $^{(a)}$, Jesús Rodríguez-Otero ${ }^{(a)}$, Enrique M. Cabaleiro-Lago ${ }^{(b)}$, Lucas \\ Azevedo dos Santos ${ }^{(\mathrm{c})}$ and Teodorico de Castro Ramalho ${ }^{(\mathrm{c})}$
}

(a) Centro Singular de Investigación en Química Biolóxica e Materiais Moleculares, Universidade de Santiago de Compostela, Rúa Jenaro de la Fuente, s/n 15782 Santiago de Compostela, Galicia (Spain).

r.otero@usc.es

(b) Departamento de Química Física, Facultad de Ciencias, Universidade de Santiago de Compostela, Campus de Lugo. Av. Alfonso X El Sabio, s/n 27002 Lugo, Galicia (Spain).

(c) Departamento de Química, Universidade Federal de Lavras, Campus Universitário UFLA, 37200-000 Lavras-MG (Brazil).

\begin{abstract}
Stacking interactions between substituted buckybowls (corannulene and sumanene) with fullerenes $\left(\mathrm{C}_{60}\right.$ and $\left.\mathrm{C}_{70}\right)$ were studied at the B97-D2/TZVP level. Corannulene and sumanene monomers were substituted with five and six $\mathrm{Br}, \mathrm{Cl}, \mathrm{CH}_{3}, \mathrm{C}_{2} \mathrm{H}$ or $\mathrm{CN}$ units, respectively. This work was carried out for supplement our previous work of the study of substituent effects in corannulene dimers, in which $\mathrm{C}_{60}$-like ('fullerene copy', corannulene with curvature of buckminsterfullerene, $\mathrm{C}_{60}$ ) was employed to imitate the concave-convex interactions between substituted corannulenes and fullerene $\mathrm{C}_{60}$ (Josa, D.; Rodriguez Otero, J.; Cabaleiro Lago, E. M. Phys. Chem. Chem. Phys., 2011, 13). Despite the promising results using $\mathrm{C}_{60}$-like, different trends of effects of substituent were obtained for our later calculations using full $\mathrm{C}_{60}$. So, $\mathrm{C}_{60}$-like, does not seem representative to imitate the concave-convex interactions between substituted corannulenes and $\mathrm{C}_{60}$. The calculations with fullerenes show that all substituents
\end{abstract}


provide a substantial increase of the interaction energy compared with unsubstituted buckybowls, as observed previously. However, substitution with $\mathrm{CH}_{3}$ groups is more favorable than substitution with $\mathrm{CN}$ groups, contrary to that obtained using $\mathrm{C}_{60}$-like. Sumanene substituted with six $\mathrm{CH}_{3}$ groups caused the largest effect increasing the interaction energy about $11 \mathrm{kcal} / \mathrm{mol}$ compared with unsubstituted corannulene for both fullerenes. $\mathrm{CH}-\pi$ interactions seem the great responsible for this increase. Stacking interactions between buckybowls and fullerene $\mathrm{C}_{70}$ show interaction energies quite similar to those obtained with $\mathrm{C}_{60}$. Therefore, it is not expected that buckybowls evaluated to specifically bind one of the fullerenes when exposed to the $C_{60} / C_{70}$ mixture.

\section{Introduction}

The search for molecular receptors for fullerenes is a very attractive field of

research in the last years. ${ }^{1}$ Several compounds have been explored in pursuit of more effective and selective fullerene receptors. ${ }^{2-8}$ A promising strategy to design new molecular receptors for fullerenes is to use the concave-convex complementarity. In this context, the curved polynuclear aromatic hydrocarbons, also known as buckybowls or fullerene fragments, seem ideal candidates given that the concave surface of one buckybowl can fits highly to the convex surface of the fullerenes by concave-convex 'ball-and-socket' interactions. ${ }^{4}$

The first stacking interaction between buckybowls and fullerenes was reported in 2005 by Georghiou and co-workers for complexes between penta and decasubstituted corannulenes with $\mathrm{C}_{60}$ in toluene solution. ${ }^{9}$ Despite the promising results, the experiments did not proved the existence of strong $\pi \cdots \pi$ interactions between corannulenes and fullerenes. The association constants obtained were relatively small and highly dependent of substituents, so that one could argue that the true interaction that bound the complex was that taking place between the fullerene and the edge substituents of corannulene and not the $\pi \cdots \pi$ interaction between corannulene and fullerene.

Fortunately, two years later, Sygula and co-workers synthesized the molecular tweezers (a buckycatcher, $\mathrm{C}_{60} \mathrm{H}_{28}$ ) made up two units of corannulene that can trap one fullerene and confirmed that the strength of the interaction is indeed from pure concave-convex $\pi \cdots \pi$ interactions between convex faces of fullerene and concave faces 
of the two subunits of suitably oriented corannulene. ${ }^{4}$ Thenceforth, predicting how to modify this buckycatcher to improve their efficiency and selectivity have been become a subject the great interest.

Undoubtedly, the success in designing of efficient systems requires depth knowledge of the characteristics of the $\pi \cdots \pi$ interactions. However, an accurate description of $\pi \cdots \pi$ interactions is a challenging task for quantum chemistry methods in general. $^{10-12}$

Although the development of new types of functionals ${ }^{13,14}$ and DFT-D methods ${ }^{15,16}$ taking into account the dispersion contribution, allows the theoretical estimation of the interaction energy for the molecular tweezers designed by Sygula et $a l^{4}$, a huge range in the estimates (from 21 to $43 \mathrm{kcal} / \mathrm{mol}$ ) were obtained depending on the DFT model used. ${ }^{18-20}$

Recently, we have performed a detailed evaluation of the performance of DFT-D, M05-2X, M06-2X functionals for studying $\pi \cdots \pi$ interactions. ${ }^{12}$ On the other hand, Janowski et al. have been performed a benchmark for corannulene dimers at the QCISD(T)/aug-cc-pVTZ. ${ }^{21}$ Both studies show that B97-D2 seems a good approach for studies of concave-convex $\pi \cdots \pi$ interactions. In addition, together with resolution of identity (RI) approximation, ${ }^{17}$ this approach enables excellent results with a noticeably smaller computational cost.

In order to evaluate the effect of the substituents on concave-convex $\pi \cdots \pi$ interactions we have carried out a DFT-D study of a series of complexes between penta-substituted corannulene $\left(\mathrm{Br}, \mathrm{Cl}, \mathrm{CH}_{3}, \mathrm{C}_{2} \mathrm{H}\right.$ and $\left.\mathrm{CN}\right)$ and $\mathrm{C}_{60}$-like, a 'fullerene copy' of $\mathrm{C}_{60} \cdot{ }^{22}$ Despite the promising results, different trends were obtained for the effects of substituents regarding to our later study using fullerene $\mathrm{C}_{60}$. Therefore, the goal of the present work is to supplement our previous work.

\section{Computational details}

All complexes evaluated were fully optimized at the B97-D2/TZVP level using resolution of identity approximation (RI) implemented in TURBOMOLE 5.10 program suite. $^{23}$

All Counterpoise corrections were applied to reported interaction energies to avoid basis set superposition error (BSSE). ${ }^{24}$ 


\section{Results and discussion}

A series of complexes composed by substituted buckybowls (corannulene and sumanene) with fullerenes $\left(\mathrm{C}_{60}\right.$ and $\left.\mathrm{C}_{70}\right)$ were evaluated at the B97-D2/TZVP level. Stacking interactions using corannulene and sumanene face of the fullerenes were taking into account in this work in order to obtain the side of the fullerenes more favorable for interacting with buckybowls. All complexes were constructed by aligning of central ring of buckybowl with central ring of corannulene or sumanene face of fullerenes given in Figure 1.

\section{Unsubstituted complexes}

As can be seen from Table 1, sumanene bowl in both concave (in the interacting side of fullerenes) and convex (buckybowl) side increases the interaction regarding to corannulene. However, the effect the sumanene in the convex side is more favorable. These results are similar than obtained for buckybowls complexes between corannulene and sumanene. $^{12}$

As reported previously by Denis, ${ }^{25}$ sumanene show three hydrogen atoms in $\mathrm{CH}_{2}$ groups absent in corannulene than can interact through $\mathrm{CH}-\pi$ interactions with fullerenes. So, $\mathrm{CH}-\pi$ interactions are largely responsible by a better catcher ability of sumanene compared to corannulene.

A series of stacking interactions between unsubstituted corannulene and sumanene with different faces of $\mathrm{C}_{70}$ were also evaluated in this work. Values of interaction energy of $-17.16,-18.00,-17.33,-18.57,-19.53$ and $-20.49 \mathrm{kcal} / \mathrm{mol}$ were obtained for corannulene $\cdots \mathrm{C}_{70}$ (cora-1 face), corannulene ${ }^{\cdots} \mathrm{C}_{70}$ (cora-2 face), corannulene ${ }^{\cdots} \mathrm{C}_{70}$ (suma face), sumanene ${ }^{\cdots} \mathrm{C}_{70}$ (cora-1 face), sumanene ${ }^{\cdots} \mathrm{C}_{70}$ (cora-2 face) and sumanene ${ }^{\cdots} \mathrm{C}_{70}$ (suma face), respectively. Unfortunately, these results are quite similar to that obtained with $\mathrm{C}_{60}$ (Table 1). Therefore, it is not expected that buckybowls evaluated to specifically bind one of the fullerenes when exposed to the $\mathrm{C}_{60} / \mathrm{C}_{70}$ mixture.

Despite previous work of the stacking interactions between buckybowls and fullerenes also show an increase in the interaction of the sumanene ${ }^{\cdots} \mathrm{C}_{60}$ complex regarding to corannulene ${ }^{\cdots} \mathrm{C}_{60}$. Similar interaction energy was obtained for corannulene and sumanene complexes with $\mathrm{C}_{70}$ at the M06-2X/6-311G level with BSSE 
uncorrected. ${ }^{25}$ On the other hand, calculations at the same level with BSSE-corrected have shown similar trends than those obtained in this work. These results confirm that disregarding of the BSSE correction for curved complex may lead to unreliable interaction energies. In fact, the underestimation of M06-2X is not due to the BSSE correction. It is due to the weakness of M06-2X for studying complexes with curved monomers, as discussed in detail in our previous study. ${ }^{12}$

\section{Substituted complexes}

Nowadays, predict how to modify the traditional tweezers to improve their efficiency and selectivity is the great interest. The modification of the tweezers by a different functionalization of buckybowls, which constitute the main part of tweezers, could improve their efficiency and selectivity. In this context, substituents may exert a modulatory effect and enable a better concave-convex interaction with fullerenes.

Recently, we have studied the substituent effects on corannulene using $\mathrm{C}_{60}$-like, a 'fullerene copy' to imitate the concave-convex interaction between substituted corannulene and $\mathrm{C}_{60}{ }^{22}$ Our results showed that introduction of substituents in the structure of buckybowls with different acceptor/donor character can change substantially the interaction. In addition, corannulenes substituted with five alternating $\mathrm{Br}, \mathrm{Cl}, \mathrm{CH}_{3}, \mathrm{C}_{2} \mathrm{H}$ and $\mathrm{CN}$ units behave as a better buckycatcher than the unsubstituted corannulene. Although $\mathrm{C}_{60}$-like proposed by Sygula and co-workers ${ }^{26}$ provide a considerable computational cost reduction, different catchers ability were obtained in our later work using the fullerene $\mathrm{C}_{60}$. So, $\mathrm{C}_{60}$-like, does not seem representative to imitate the concave-convex interaction between substituted corannulene and $\mathrm{C}_{60}$. Therefore, a supplementary work using the buckminsterfullerene, $\mathrm{C}_{60}$ is very advisable.

A series of stacking interactions between substituted buckybowls (corannulene and sumanene) with fullerenes $\left(\mathrm{C}_{60}\right.$ and $\left.\mathrm{C}_{70}\right)$ were evaluated in this work in order to known the true ability of substituted buckybowls as fullerene receptors. Corannulene and sumanene monomers were substituted with five and six $\mathrm{Br}, \mathrm{Cl}, \mathrm{CH}_{3}, \mathrm{C}_{2} \mathrm{H}$ or $\mathrm{CN}$ units, respectively. Figure 2 shows one of complexes investigated and Table 1 summarizes the interaction energies and equilibrium distances values obtained at the B97-D2/TZVP level.

As commented above, similar results were obtained for complexes with fullerenes $\mathrm{C}_{60}$ and $\mathrm{C}_{70}$. So, only stacking interactions using equivalent face of $\mathrm{C}_{70}$ that 
buckybowl interacting were evaluated in this work. Although, complexes using cora-2 face of $\mathrm{C}_{70}$ showed interaction energies about $1 \mathrm{kcal} / \mathrm{mol}$ higher than those obtained with cora-1 face. Only, complexes with cora-1 face (higher symmetry) were evaluated for substituted corannulenes, which provides a considerable reduction of the computational cost.

Unfortunately, a different ranking of catchers was obtained for substituted corannulene complexes with $\mathrm{C}_{60}$ and $\mathrm{C}_{60}$-like (Table 1). In fact, calculations using $\mathrm{C}_{60}$ show that substitution with $\mathrm{CH}_{3}$ groups is more favorable than substitution with $\mathrm{CN}$ groups, obtained using $\mathrm{C}_{60}$-like. Again, our results show that $\mathrm{CH}-\pi$ interaction plays an important role to improve the recognition of fullerenes.

Sumanene substituted with six $\mathrm{CH}_{3}$ groups causes the large effect, increasing the interaction energy about $11 \mathrm{kcal} / \mathrm{mol}$, compared with unsubstituted corannulene. Although sumanene shows a better catcher ability than corannulene for stacking interaction with both fullerenes evaluated, the introduction of substituents in their structure provides similar effects than those obtained for corannulene.

As can be seen in Table 1 there is a substantial increase in the interaction energy of complexes when different substituents were placed in corannulene and sumanene monomers. However, only very small differences in the equilibrium distance were found. In general, the introduction of substituents on corannulene stacking interactions with fullerenes $\mathrm{C}_{60}$ and $\mathrm{C}_{70}$ produces a slight decrease in the equilibrium distance values, except for corannulene-5CN $\cdots \mathrm{C}_{60}$ (sumanene face of $\mathrm{C}_{60}$ ). On the other hand, the introduction of substituents on sumanene yields a slight increase, except for $\mathrm{CH}_{3}$ groups that show very similar equilibrium distances than using unsubstituted sumanene.

On the other hand, comparison between equilibrium distances obtained in this work for complexes between substituted corannulenes with $\mathrm{C}_{60}$ and those obtained previously using $\mathrm{C}_{60}$-like shows a slight shortening of equilibrium distances, except for corannulene with $\mathrm{CN}$ groups that increases the equilibrium distance.

As a way of checking the changes introduced in the bowls by the substituents, Table 2 lists the values of two important geometric parameters. $R$ is the interplanar distance between the planes formed by hub and rim atoms, respectively; it represents the bowl depth. POAV is the pyramidalization angle ( $\pi$-orbital axis vector) as proposed by Haddon. ${ }^{27}$ The POAV angle allows the description of local curvature of a conjugated system and is defined as the angle between the $\mathrm{C}-\mathrm{C}$ bond and the vector perpendicular to the pyramidal base of three idealized $\mathrm{C}-\mathrm{C}$ bonds. Geometric results indicate that 
substituents give rise to small changes in the curvature of corannulene and sumanene bowls. So, there was not a clear relationship between the curvature of bowl and the changes on the interaction energy generated by addition of substituents in the bowl.

In order to analyze in more detail the balance of energy contributions to the stability of the complexes, the interaction energy was decomposed according to a simple method. So, the two contributions of the model employed were taken into account; that is, the pure B97 interaction energy and the empirical dispersion contribution to the interaction energy. Results in Table 3 show that dispersion plays a very important role in the interaction energy of complexes.

The ranking of the catchers show a strong relationship with dispersion, except for $\mathrm{CN}$ substituents that show similar or slight higher catcher ability and smaller dispersion contribution that obtained with $\mathrm{C}_{2} \mathrm{H}$. Despite substitution with $\mathrm{CN}$ groups does not cause the largest effect on interactions with fullerenes evaluated, the results show a most favorable pure B97 interaction energy for this substitution compared to the others substitutions evaluated, as obtained previously. ${ }^{22}$ These results show that both dispersive and electrostatic effects are important to justify the behavior of substituents in concave-convex $\pi \cdots \pi$ interactions.

\section{Conclusions}

Stacking interactions between substituted buckybowls (corannulene and sumanene) with fullerenes $\left(\mathrm{C}_{60}\right.$ and $\left.\mathrm{C}_{70}\right)$ were studied at the B97-D2/TZVP level in order to known the ability of these substituted buckybowls as 'buckycatchers'.

All substituted buckybowls evaluated behave as a better buckycatcher than the unsubstituted buckybowls. Sumanene substituted with six $\mathrm{CH}_{3}$ group was the most stable complex. $\mathrm{CH}-\pi$ interactions are largely responsible by this result.

Stacking interactions between buckybowls evaluated and fullerene $\mathrm{C}_{70}$ show interaction energies quite similar to that obtained with $\mathrm{C}_{60}$. Therefore, it is not expected that buckybowls evaluated to specifically bind one of the fullerenes when exposed to the $\mathrm{C}_{60} / \mathrm{C}_{70}$ mixture.

The ranking of the catchers show a strong relationship with dispersion. On the other hands, the dispersion is not only factor responsible by interaction energy. As can be observed, sumanene-6CN monomer shows a better catcher ability than 
sumanene- $6 \mathrm{C}_{2} \mathrm{H}$. However, sumanene- $6 \mathrm{C}_{2} \mathrm{H}$ shows a higher dispersion than sumanene-6CN.

The results of this work show that $\mathrm{C}_{60}$-like used in our previous work does not seem representative for reproducing the concave-convex interactions between substituted corannulene and $\mathrm{C}_{60}$. The weakness of the $\mathrm{C}_{60}$-like can be due the small size of this 'fullerene copy' (corannulene with curvature of $\mathrm{C}_{60}, \mathrm{C}_{20} \mathrm{H}_{10}$ ). Moreover, possibly, the ten hydrogen atoms attached to the dangling bonds of $\mathrm{C}_{60}$-like can interact with the substituents of the corannulene. Additionally, $\mathrm{C}_{60}$-like shows a different molecular electrostatic potential map than that obtained for the real $\mathrm{C}_{60}$.

\section{Acknowledgments}

The authors want to express their gratitude to the CESGA (Centro de Supercomputación de Galicia) for the use of their computers. D. J. thanks the Spanish Ministry of Education for FPU scholarship. 
Table 1. Interaction energies, $E_{\mathrm{Int}}$, $(\mathrm{kcal} / \mathrm{mol})$ and equilibrium distances, $d_{\mathrm{eq}}$, $(\AA)$ for complexes between buckybowls with corannulene or sumanene face of fullerenes. All calculations were performed at the B97-D2/TZVP level. Calculations at the B97-D2/6-31+G* using $\mathrm{C}_{60}-\mathrm{like}_{\mathrm{k}}$ are given in parentheses for comparison.

\begin{tabular}{|c|c|c|c|c|c|c|c|c|}
\hline & \multicolumn{4}{|c|}{$\mathrm{X}=\mathrm{C}_{60}$} & \multicolumn{4}{|c|}{$\mathrm{X}=\mathrm{C}_{70}$} \\
\hline & \multirow{2}{*}{$\begin{array}{c}\text { Cora face of } \mathrm{C}_{60} \\
E_{\text {Int }}\end{array}$} & & \multicolumn{2}{|c|}{ Suma face of $C_{60}$} & \multicolumn{2}{|c|}{ Cora- 1 face of $\mathrm{C}_{70}$} & \multicolumn{2}{|l|}{ Suma face of $\mathrm{C}_{70}$} \\
\hline & & $d_{\mathrm{eq}}$ & $E_{\mathrm{Int}}$ & $d_{\mathrm{eq}}$ & $E_{\text {Int }}$ & $d_{\mathrm{eq}}$ & $E_{\mathrm{Int}}$ & $d_{\mathrm{eq}}$ \\
\hline Corannulene $\cdots X$ & $-17.03(-14.16)$ & $3.456(3.51)$ & -17.26 & 3.563 & -17.16 & 3.447 & & \\
\hline Corannulene-5Br $\cdots X$ & $-23.06(-20.44)$ & $3.399(3.45)$ & -22.90 & 3.523 & -23.04 & 3.385 & & \\
\hline Corannulene- $5 \mathrm{Cl} \cdots \mathrm{X}$ & $-20.60(-18.56)$ & $3.414(3.47)$ & -20.49 & 3.534 & -20.58 & 3.408 & & \\
\hline Corannulene- $5 \mathrm{CH}_{3} \cdots \mathrm{X}$ & $-23.82(-19.23)$ & $3.394(3.44)$ & -23.90 & 3.512 & -23.87 & 3.378 & & \\
\hline Corannulene- $5 \mathrm{C}_{2} \mathrm{H} \cdots \mathrm{X}$ & $-22.31(-18.06)$ & $3.426(3.47)$ & -22.17 & 3.554 & -22.20 & 3.410 & & \\
\hline Corannulene-5CN $\cdots X$ & $-22.28(-23.35)$ & $3.442(3.43)$ & -21.91 & 3.593 & -22.10 & 3.434 & & \\
\hline Sumanene $\cdots X$ & -18.47 & 3.502 & -20.40 & 3.450 & & & -20.49 & 3.453 \\
\hline Sumanene- $6 \mathrm{Br} \cdots \mathrm{X}$ & -25.40 & 3.528 & -26.50 & 3.507 & & & -27.03 & 3.496 \\
\hline Sumanene- $6 \mathrm{Cl} \cdots \mathrm{X}$ & -22.34 & 3.532 & -23.40 & 3.512 & & & -23.78 & 3.505 \\
\hline Sumanene- $6 \mathrm{CH}_{3} \cdots \mathrm{X}$ & -26.43 & 3.511 & -27.61 & 3.459 & & & -28.10 & 3.446 \\
\hline Sumanene- $6 \mathrm{C}_{2} \mathrm{H} \cdots \mathrm{X}$ & -24.67 & 3.534 & -25.88 & 3.510 & & & -26.51 & 3.508 \\
\hline Sumanene-6CN $\cdots X$ & -25.51 & 3.521 & -26.36 & 3.537 & & & -27.02 & 3.511 \\
\hline
\end{tabular}


Table 2. Geometric parameter $R$ (in $\AA$ ), and POAV angles at the hub position (degrees) obtained at the B97-D2/TZVP level.

\begin{tabular}{|c|c|c|c|c|c|c|c|c|}
\hline & \multicolumn{4}{|c|}{$\mathrm{X}=\mathrm{C}_{60}$} & \multicolumn{4}{|c|}{$\mathrm{X}=\mathrm{C}_{70}$} \\
\hline & \multicolumn{2}{|c|}{ Cora face of $\mathrm{C}_{60}$} & \multicolumn{2}{|r|}{ Suma face of $\mathrm{C}_{60}$} & \multicolumn{2}{|c|}{ Cora- 1 face of $C_{70}$} & \multicolumn{2}{|c|}{ Suma face of $\mathrm{C}_{70}$} \\
\hline & $R$ & POAV & $R$ & POAV & $R$ & POAV & $R$ & POAV \\
\hline Corannulene $\cdots X$ & 0.902 & 8.38 & 0.894 & $8.28,8.31,8.34$ & 0.909 & 8.42 & & \\
\hline Corannulene-5Br $\cdots \mathrm{X}$ & 0.882 & 8.26 & 0.871 & $8.11,8.18,8.19,8.21$ & 0.878 & 8.22 & & \\
\hline Corannulene- $5 \mathrm{Cl} \cdots \mathrm{X}$ & 0.881 & 8.25 & 0.873 & $8.12,8.17,8.21$ & 0.888 & 8.30 & & \\
\hline Corannulene- $5 \mathrm{CH}_{3} \cdots \mathrm{X}$ & 0.914 & 8.51 & 0.904 & $8.36,8.41,8.42,8.45,8.48$ & 0.915 & 8.51 & & \\
\hline Corannulene- $5 \mathrm{C}_{2} \mathrm{H} \cdots \mathrm{X}$ & 0.921 & 8.52 & 0.906 & $8.33,8.42,8.43,8.44$ & 0.910 & 8.44 & & \\
\hline Corannulene-5CN $\cdots X$ & 0.924 & 8.55 & 0.911 & $8.34,8.46,8.47,8.49,8.51$ & 0.916 & 8.51 & & \\
\hline Sumanene $\cdots X$ & 1.093 & $8.42,8.57,8.64$ & 1.067 & 8.43 & & & 1.076 & $8.46,8.49,8.5$ \\
\hline Sumanene- $6 \mathrm{Br} \cdots \mathrm{X}$ & 1.096 & $8.63,8.71$ & 1.058 & 8.50 & & & 1.061 & $8.50,8.52,8.5$ \\
\hline Sumanene- $6 \mathrm{Cl} \cdots \mathrm{X}$ & 1.098 & $8.61,8.69,8.70$ & 1.063 & 8.49 & & & 1.065 & $8.50,8.52$ \\
\hline Sumanene- $6 \mathrm{CH}_{3} \cdots \mathrm{X}$ & 1.115 & $8.59,8.74,8.77$ & 1.091 & 8.59 & & & 1.091 & $8.60,8.61$ \\
\hline Sumanene- $6 \mathrm{C}_{2} \mathrm{H} \cdots \mathrm{X}$ & 1.138 & $8.79,8.84$ & 1.104 & 8.68 & & & 1.108 & $8.68,8.70$ \\
\hline Sumanene-6CN $\cdots X$ & 1.126 & $8.75,8.76,8.79$ & 1.101 & 8.68 & & & 1.102 & $8.66,8.68,8.7($ \\
\hline
\end{tabular}


Table 3. B97 interaction energy and dispersion contribution for complexes obtained at the B97-D2/TZVP level ( $\mathrm{kcal} / \mathrm{mol})$.

\begin{tabular}{|c|c|c|c|c|c|c|c|c|}
\hline & \multicolumn{2}{|c|}{$\begin{array}{r}\mathrm{X}=\mathrm{C}_{60} \\
\text { Cora face of } \mathrm{C}_{60}\end{array}$} & \multicolumn{2}{|c|}{ Suma face of $\mathrm{C}_{60}$} & \multicolumn{2}{|c|}{$\begin{aligned} & \mathrm{X}=\mathrm{C}_{70} \\
& \text { Cora-1 face of } \mathrm{C}_{70}\end{aligned}$} & \multicolumn{2}{|c|}{ Suma face of $\mathrm{C}_{70}$} \\
\hline & B97 & Dispersion & B97 & Dispersion & B97 & Dispersion & B97 & Dispersion \\
\hline Corannulene $\cdots X$ & 16.17 & -33.20 & 16.43 & -33.69 & 16.21 & -33.37 & & \\
\hline Corannulene-5Br $\cdots X$ & 21.07 & -44.13 & 20.77 & -43.67 & 21.10 & -44.14 & & \\
\hline Corannulene-5Cl $\cdots \mathrm{X}$ & 19.36 & -39.96 & 19.12 & -39.61 & 19.53 & -40.11 & & \\
\hline Corannulene- $5 \mathrm{CH}_{3} \cdots \mathrm{X}$ & 21.39 & -45.21 & 21.44 & -45.34 & 21.78 & -45.65 & & \\
\hline Corannulene- $5 \mathrm{C}_{2} \mathrm{H} \cdots \mathrm{X}$ & 20.10 & -42.41 & 19.71 & -41.88 & 19.83 & -42.03 & & \\
\hline Corannulene-5CN $\cdots X$ & 18.60 & -40.88 & 18.33 & -40.24 & 18.24 & -40.34 & & \\
\hline Sumanene $\cdots X$ & 19.17 & -37.64 & 20.47 & -40.87 & & & 20.65 & -41.14 \\
\hline Sumanene- $6 \mathrm{Br} \cdots \mathrm{X}$ & 23.66 & -49.06 & 25.69 & -52.19 & & & 26.22 & -53.25 \\
\hline Sumanene- $6 \mathrm{Cl} \cdots \mathrm{X}$ & 21.70 & -44.04 & 23.97 & -47.37 & & & 24.23 & -48.01 \\
\hline Sumanene- $6 \mathrm{CH}_{3} \cdots \mathrm{X}$ & 25.93 & -52.36 & 26.94 & -54.55 & & & 27.67 & -55.77 \\
\hline Sumanene- $6 \mathrm{C}_{2} \mathrm{H} \cdots \mathrm{X}$ & 22.98 & -47.65 & 25.30 & -51.18 & & & 25.30 & -51.81 \\
\hline Sumanene-6CN $\cdots \mathrm{X}$ & 20.79 & -46.30 & 22.16 & -48.52 & & & 23.13 & -50.15 \\
\hline
\end{tabular}




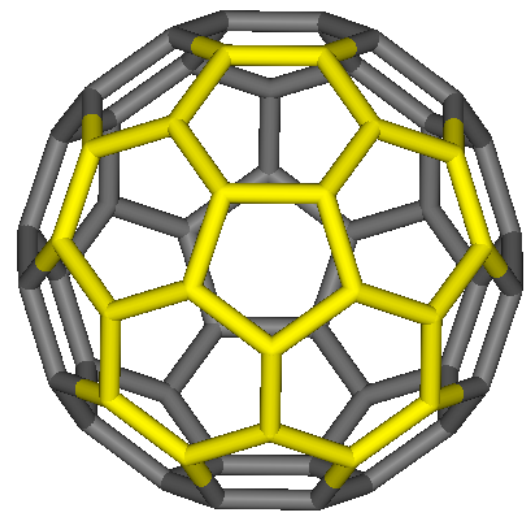

Cora face of $\mathbf{C}_{60}$

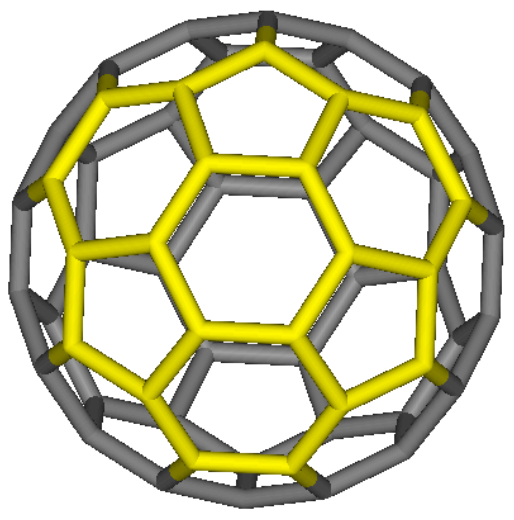

Suma face of $\mathbf{C}_{60}$

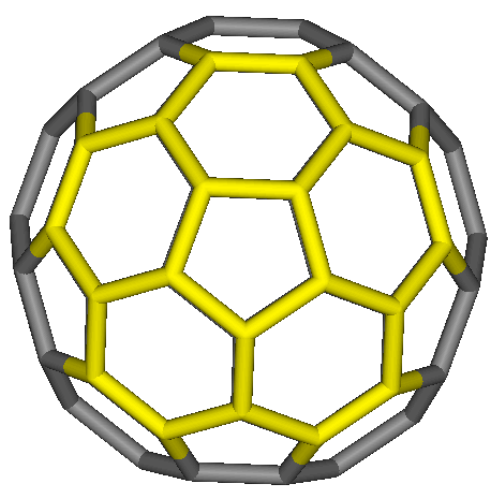

Cora-1 face of $\mathbf{C}_{70}$

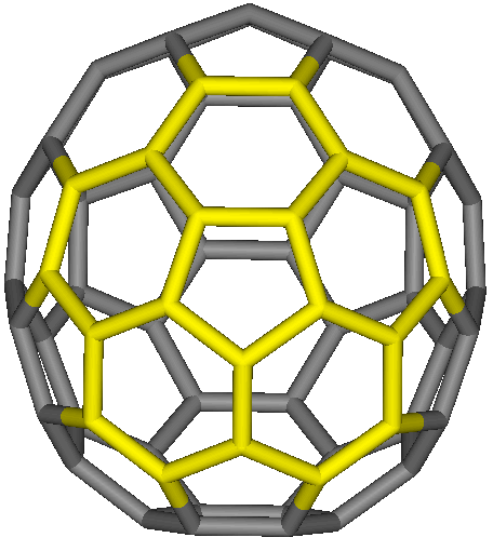

Cora-2 face of $\mathbf{C}_{70}$

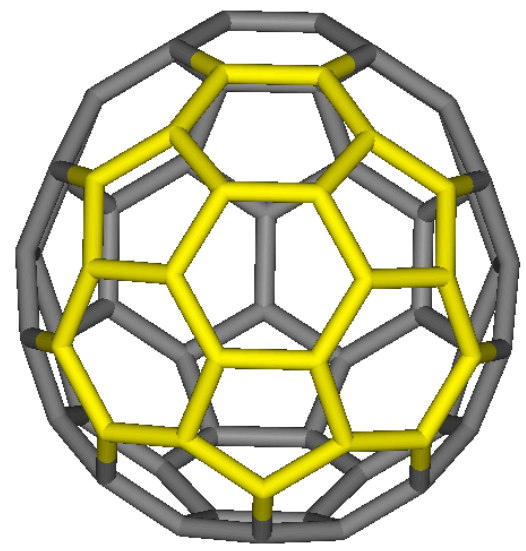

Suma face of $\mathbf{C}_{\mathbf{7 0}}$

Figure 1. Faces of the fullerenes used in the stacking interactions with buckybowls. 

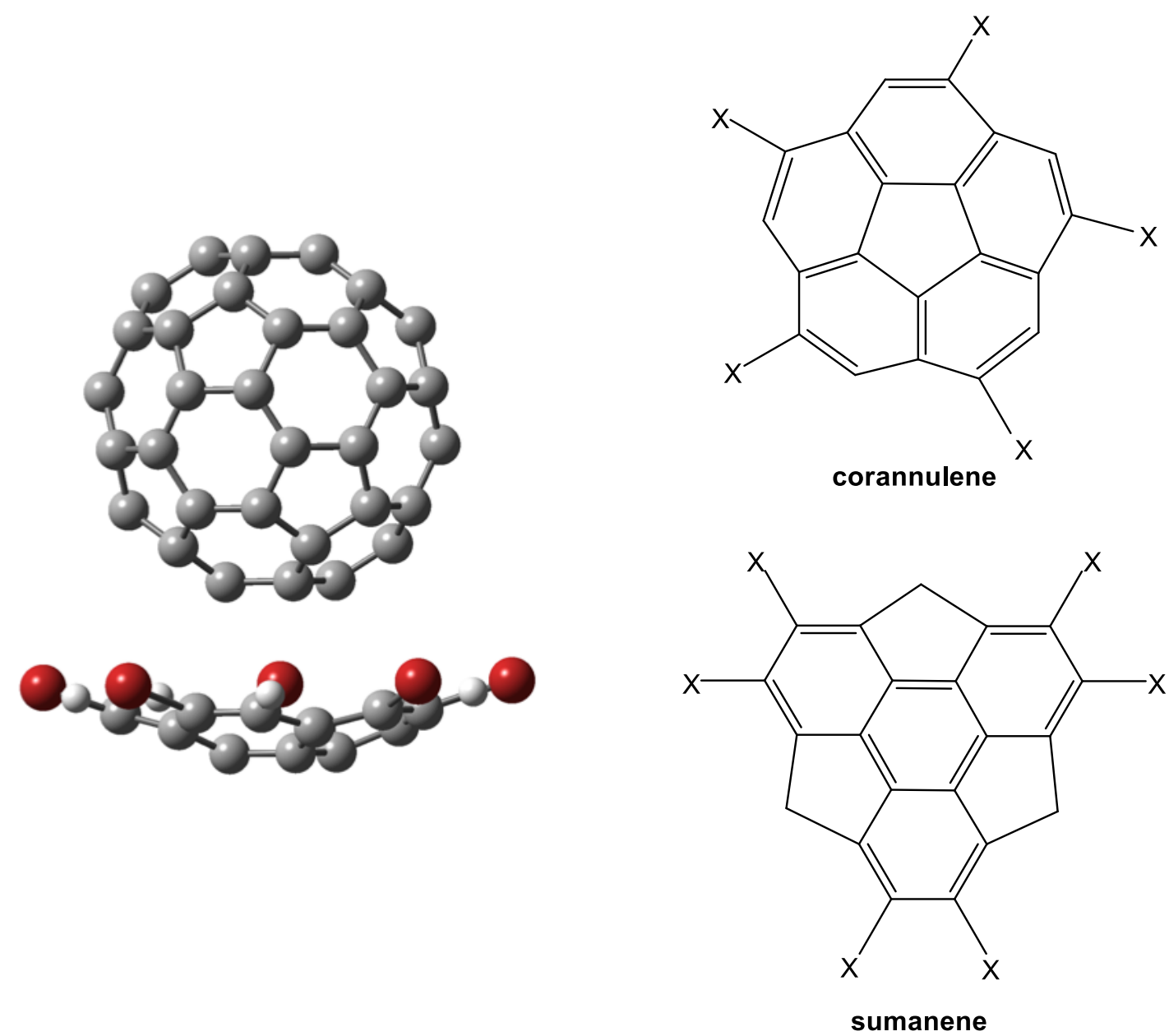

$\mathrm{X}=\mathrm{H}, \mathrm{Br}, \mathrm{Cl}, \mathrm{CH}_{3}, \mathrm{C}_{2} \mathrm{H}, \mathrm{CN}$

Figure 2. A Complex formed by corannulene-5Br and fullerene (cora face of $\mathrm{C}_{60}$ ) (left). Substituted corannulene and sumanene monomer studied (right). 


\section{References}

(1) Pérez, E. M.; Martín, N. Pure Appl. Chem. 2010, 82, 523.

(2) Shoji, Y.; Tashiro, K.; Aida, T. J. Am. Chem. Soc. 2010, 132, 5928.

(3) Zhang, E.-X.; Wang, D.-X.; Zheng, Q.-Y.; Wang, M.-X. Org. Lett. 2008, $10,2565$.

(4) Sygula, A.; Fronczek, F. R.; Sygula, R.; Rabideau, P. W.; Olmstead, M. M. J. Am. Chem. Soc. 2007, 129, 3842.

(5) Huerta, E.; Isla, H.; Perez, E. M.; Bo, C.; Martin, N.; de Mendoza, J. J. Am. Chem. Soc. 2010, 132, 5351.

(6) Tashiro, K.; Aida, T. Chem. Soc. Rev. 2007, 36, 189.

(7) Canevet, D.; Gallego, M.; Isla, H.; de Juan, A.; Perez, E. M.; Martin, N. J. Am. Chem. Soc. 2011, 133, 3184.

(8) Pérez, E. M.; Martín, N. Chem. Soc. Rev. 2008, 37, 1512.

(9) Georghiou, P. E.; Tran, A. H.; Mizyed, S.; Bancu, M.; Scott, L. T. J. Org. Chem. 2005, 70, 6158 .

(10) Cerny, J.; Hobza, P. Phys. Chem. Chem. Phys. 2007, 9, 5291.

(11) Riley, K. E.; Hobza, P. Wiley Interdiscip. Rev. Comput. Mol. Sci. 2011, 1,3 .

(12) Josa, D.; Rodríguez-Otero, J.; Cabaleiro-Lago, E. M.; Rellán-Piñeiro, M. Chem. Phys. Lett. 2013, 557, 170. 161103.

(13) Zhao, Y.; Schultz, N. E.; Truhlar, D. G. J. Chem. Phys. 2005, 123,

(14) Zhao, Y.; Truhlar, D. G. Theor. Chem. Acc. 2008, 120, 215.

(15) Grimme, S. J. Comput. Chem. 2004, 25, 1463.

(16) Grimme, S.; Antony, J.; Schwabe, T.; Muck-Lichtenfeld, C. Org. Biomol. Chem. 2007, 5, 741.

(17) Skylaris, C.-K.; Gagliardi, L.; Handy, N. C.; Ioannou, A. G.; Spencer, S.; Willetts, A. J. Mol. Struct. (Theochem) 2000, 501-502, 229.

(18) Muck-Lichtenfeld, C.; Grimme, S.; Kobryn, L.; Sygula, A. Phys. Chem. Chem. Phys. 2010, 12, 7091.

(19) Wong, B. M. J. Comput. Chem. 2009, 30, 51.

(20) Zhao, Y.; Truhlar, D. G. Phys. Chem. Chem. Phys. 2008, 10, 2813.

(21) Janowski, T.; Pulay, P.; Sasith Karunarathna, A. A.; Sygula, A.; Saebø, S. Chem. Phys. Lett. 2011, 512, 155.

(22) Josa, D.; Rodriguez Otero, J.; Cabaleiro Lago, E. M. Phys. Chem. Chem. Phys. 2011, 13, 21139.

(23) Ahlrichs, R.; Bär, M.; Häser, M.; Horn, H.; Kölmel, C. Chem. Phys. Lett. 1989, $162,165$.

(24) Boys, S. F.; Bernardi, F. Mol. Phys. 1970, 19, 553.

(25) Denis, P. A. Chem. Phys. Lett. 2011, 516, 82.

(26) Sygula, A.; Saebø, S. Int. J. Quantum Chem. 2009, 109, 65.

(27) Haddon, R. C. J. Am. Chem. Soc. 1990, 112, 3385. 